\title{
Modulatory effects of rutin on the expression of cytochrome P450s and antioxidant enzymes in human hepatoma cells
}

\author{
SERDAR KARAKURT* \\ Department of Biochemistry \\ Faculty of Science \\ Selcuk University, Konya, Turkey
}

Accepted July 27, 2016

Published online August 2, 2016

\begin{abstract}
Expression of a drug and xenobiotic metabolizing enzymes, cytochrome P450s (CYPs), and antioxidant enzymes can be modulated by various factors. The flavonoid rutin was investigated for its anti-carcinogen and protective effects as well as modulatory action on CYPs and phase II enzymes in human hepatocellular carcinoma cells. Rutin inhibited proliferation of HEPG2 cells in a dose-dependent manner with the $I C_{50}$ value of $52.7 \mu \mathrm{mol} \mathrm{L}-1$ and invasion of HEPG2 cells (21.6\%, $p=0.0018)$ and colony formation of those invaded cells $(57.4 \%, p<0.0001)$. Rutin treatment also significantly increased early/late-stage apoptosis in HEPG2 cells $(28.9 \%$, $p<0.001)$. Treatment by rutin significantly inhibited protein expressions of cytochrome P450-dependent CYP3A4 $(75.3 \%$, $p<0.0001)$, elevated CYP1A1 enzymes (1.7-fold, $p=0.0084$ ) and increased protein expressions of antioxidant and phase II reaction catalyzing enzymes, NQO1 (2.42-fold, $p<0.0001)$ and GSTP1 (2.03-fold, $p<0.0001)$. Besides, rutin treatment significantly inhibited mRNA expression of CYP3A4 (73.2 \%, $p=0.0014)$. Also, CYP1A1, NQO1 and GSTP1 mRNA expressions were significantly increased 2.77-fold ( $p=0.029), 4.85$ fold ( $p=0.0051)$ and 9.84-fold $(p<0.0001)$, respectively.
\end{abstract}

Keywords: rutin, cytochrome P450s, phase II enzymes, cell proliferation, HEPG2

Hepatocellular carcinoma (HCC) is one of the most common malignant tumors, with 700,000 deaths annually worldwide; every year 14,000 new cases have been recorded (1). The main reason for the occurrence of HCC is hepatitis B (the incidence is 100-fold higher than in the uninfected population) and hepatitis $C$ virus infection, as well as alcohol overconsumption, metabolic liver diseases, obesity and type II diabetes $(2,3)$. $70-80 \%$ of HCC resulted from cirrhosis. Depending on the stage of liver cancer, surgery, chemotherapy or radiotherapy is used for the treatment. On the other hand, development of new strategies is required for curative treatment.

Nowadays, naturally occurring phenolic compounds have become popular for the treatment of several diseases, including diabetes, cardiovascular diseases and cancer. Up

\footnotetext{
*Correspondence; e-mail: kserdar1@yahoo.com
} 
to now, 4,000 chemically different flavonoids have been reported and categorized as flavonols, flavones, flavanones, catechins, anthocyanidins and chalcones (4). During daily intake, approximately $3-80 \mathrm{mg}$ of flavonoids is consumed and average intake of flavonoids decreases mortality in several diseases including coronary heart disease and cancer (5). One of the naturally occurring flavonoids of plant origin is rutin, quercetin-3-rhamnosylglucoside. This bioflavonoid cannot be synthesized by humans or animals; hence, it can be solely obtained from plant products (6). Administration of rutin to rat and rabbit causes the formation of 3,4-dihydroxyphenylacetic acid, 3-methoxy-4-hydroxyphenylacetic acid and $m$-hydroxyphenylacetic acid in urine, and quercetin-3'-O-methyl ether in bile (7). The microflora in lower gut hydrolyzes rutin to quercetin and isoquercetin, which are absorbed by the small intestine wall (8). Binding properties of rutin to metal ions, especially chelating $\mathrm{Fe}^{2+}$ and $\mathrm{Fe}^{3+}$, makes it one of the most important antioxidants since these metal ions are crucial for initiation of oxygen free-radical formation (9). Moreover, rutin was demonstrated to prevent cardiovascular and neurodegenerative diseases by inhibiting lipid peroxidation (10). A hundred $\mu \mathrm{mol} \mathrm{L}{ }^{-1}$ of rutin also induced apoptosis in human glioblastoma cells by affecting the cell cycle (11). Rutin possesses anti-inflammatory (inhibiting the mucosal content of platelet-activating factor, PAF) and vasoactive activity (diminishing capillary permeability) as well as antioxidant activity (scavenging of hydroxyl and superoxide radicals) (12). Also, anti-carcinogen activity of rutin against prostate, breast, lung and colon cancers was demonstrated $(13,14)$.

Metabolism of flavonoids and other xenobiotics (drugs, environmental pollutants and dietary products) was mainly accomplished by cytochrome P450 enzymes (P450s) (15). Among P450s, CYP3A4 is recognized as the main enzyme involved in the metabolism of drugs in the liver. Therefore, one of the first steps during drug development is to clarify interaction between the promising new drug and CYP3A4 (16). Being the large and flexible substrate, binding pockets allow CYP3A4 to accommodate flavonoids at multiple sites (17). Metabolism of P450s sometimes results in formation of superoxide radicals, which may cause toxicity or carcinogenesis. Hence, defense mechanism enzymes, called phase II enzymes, and antioxidants have been created to eliminate hazardous effects of P450s. Phase II enzymes, including glutathione S-transferases (GSTs) and NADPH quinone oxidoreductase I (NQO1) enzymes, cause conjugation reactions, which convert lipid soluble compounds to water soluble counterparts.

The present work investigates the in vitro effects of rutin on proliferation, migration, invasion and colony formation properties of the human liver cancer cell line HEPG2 and modulation of gene and protein expression of cytochrome P450 and antioxidant enzymes.

\section{EXPERIMENTAL}

\section{Chemicals}

Rutin and bicinchoninic acid (BCA) kit for protein determination was acquired from Sigma-Aldrich (USA). Alamar blue was purchased from Invitrogen Life Technologies (USA). The CYP3A4, CYP1A1, NQO1 antibodies were obtained from Santa Cruz (USA). GSTP1 and GAPDH were acquired from Abcam (UK). Primers were synthesized by Iontek (Turkey). Eagle's minimum essential medium (EMEM) was purchased from ATCC (Amer- 
ican Type Culture Collection, USA). All chemicals and solvents were of analytical grade and were obtained from commercial sources with the highest grade of purity available.

\section{Characterization of rutin}

The presence of functional groups and confirmation of rutin purity were done using ${ }^{1} \mathrm{H}$ NMR (Varian 400, USA) and FT-IR spectroscopy (PerkinElmer Spectrum 100, USA) in the spectral range of $4000-650 \mathrm{~cm}^{-1}$ with a resolution of $4 \mathrm{~cm}^{-1}$, using the ATR technique.

\section{Cell culture and treatment}

The human hepatocarcinoma cancer cell line, HEPG2, was provided from ATCC. Cell line was routinely cultured in EMEM supplemented with $10 \%$ fetal bovine serum (FBS), $100 \mathrm{U} \mathrm{mL}^{-1}$ penicillin, $100 \mu \mathrm{g} \mathrm{mL} \mathrm{m}^{-1}$ streptomycin and incubated at $37^{\circ} \mathrm{C}$ in a humidified atmosphere containing $5 \% \mathrm{CO}_{2}$ in air. The cells grown were harvested by trypsinization and serially subcultured. The growth medium was also used for dilution of rutin.

\section{Cell proliferation assay}

HEPG2 cells were seeded at a density ranging from $1 \times 10^{3}$ to $1 \times 10^{5}$ cells $\mathrm{mL}^{-1}$ into 96-well plate and incubated for $24 \mathrm{~h}$ at $37^{\circ} \mathrm{C}$ in $5 \% \mathrm{CO}_{2}$ atmosphere in order to determine optimum cell number. The cells were treated with various concentrations of rutin, ranging from 1 to $200 \mu \mathrm{mol} \mathrm{L}^{-1}$, to calculate the $I C_{50}$ value (half maximal inhibitory concentration). Cell viability was monitored by Alamar blue method, in which conversion of resazurin to resorufin was measured spectrophotometrically (Multiskan ${ }^{\mathrm{TM}}$ GO Microplate Spectrophotometer, Thermo Fisher, USA).

\section{Colony formation assay}

In order to evaluate the ability of rutin-treated HEPG2 cells for colony formation, the cells were plated in soft agar. Bottom agar contained $1 \%$ agar dissolved in $2 X$ growth me-

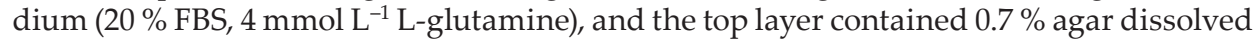
in normal growth medium (10 \% FBS, $2 \mathrm{mmol} \mathrm{L}^{-1} \mathrm{~L}$-glutamine). Top agar was then mixed with $5 \times 10^{3}$ cells and transferred over the agar base. Agar layers were then covered with EMEM and incubated at $37{ }^{\circ} \mathrm{C}$ and $5 \% \mathrm{CO}_{2}$ for 15 days. After incubation, colony fixation was performed using $3.7 \%$ formaldehyde and the cells were stained with $0.1 \%$ toluidine blue. Excess amount of the dye was cleaned with $10 \mathrm{mmol} \mathrm{L}^{-1}$ PBS.

\section{Wound healing assay}

Wound healing assay was performed using the CytoSelect ${ }^{\mathrm{TM}}$ wound healing assay kit (Cell Biolabs, USA). After two days of incubation of the cells with $I C_{50}$-equivalent concentration of rutin, the cells were detached with trypsin and $1 \times 10^{6}$ of them seeded into a 12well plate, in which a precise $0.9 \mathrm{~mm}$ gap was formed using an insert. After incubation with serum-free medium for $18 \mathrm{~h}$, the insert was gently removed and migration of the cells into the wound field was monitored. 


\section{Cell migration/invasion assay}

Invasive potential of HEPG2 cells was evaluated by BD BioCoat TM Matrigel Invasion Chambers (BD Biosciences, USA). After two days of incubation of the cells with $I C_{50}$ - equivalent concentration of rutin, $1 \times 10^{5}$ of the cells were harvested, re-suspended in $1 \% \mathrm{FBS}$ and placed in the upper chamber of the transwell. The cells in the upper chamber started to migrate to the lower chamber containing growth medium with $20 \% \mathrm{FBS}$ by incubation for $24 \mathrm{~h}$ at $37{ }^{\circ} \mathrm{C}$ in a $5 \% \mathrm{CO}_{2}$ atmosphere. After incubation, non-invaded cells were removed from the upper side of the membrane with cotton swabs. Formaldehyde $(3.7 \%)$ and methanol were used for fixation and permeabilization, respectively. The cells were stained with $1 \%$ toluidine for $15 \mathrm{~min}$ at room temperature for visualization. Invaded cells were photographed under the inverted microscope and counted.

\section{Apoptosis assays}

Flow cytometric analysis was performed to assess the apoptosis and necrosis rates of HEPG2 cells before and after the treatment with rutin. Following the treatment with $I C_{50}{ }^{-}$ equivalent concentration of rutin, the cells were incubated for 48 hours and detached with trypsin. Then, the cells were stained with Annexin V-APC and 7-AAD antibodies (BD Biosciences) at room temperature to detect the apoptosis and necrosis rates. The analyses were performed using flow cytometry (Beckman Coulter Navios, USA).

\section{cDNA synthesis and quantitative mRNA expression by real-time PCR}

Quantitative real-time RT-PCR was used to investigate the differences in the expression of mRNA of cytochrome P450 enzymes and phase II enzymes. HepG2 cells were transfected with a concentration equivalent to rutin $I C_{50}$ value for 2 days. Cells were then washed with PBS and lysed with QIAzol reagent (Qiagen, USA) for dissociation of any RNA-protein complexes. Chloroform was added for phase separation, followed by aqueous precipitation of total RNA using isopropyl alcohol. One microgram of total RNA was reversely transcribed into cDNA using a QuantiTect reverse transcription kit (Qiagen). Quantitative and qualitative analyses of RNA and cDNA were measured at NanoDrop ${ }^{\mathrm{TM}}$ 2000 (Thermo Scientific, USA). qRT-PCR was performed with primers for NQO1, GSTP1, GSTM1, CYP1A1, CYP3A4 and CYP17A1 with a QuantiTect SYBR Green PCR kit in the BioRad CFX96 real time PCR detection system (Bio-Rad, USA). Housekeeping gene, GAP$\mathrm{DH}$, which is assumed to be expressed at a constant level, was used as normalizer. Fold change was calculated from: $2^{-\Delta \Lambda C t}$

where $\Delta \Delta \mathrm{Ct}=\Delta \mathrm{Ct}($ treated $)-\Delta \mathrm{Ct}($ control $), \Delta \mathrm{Ct}($ treated $)=\Delta \mathrm{Ct}(\mathrm{CYPs})-\Delta \mathrm{Ct}(\mathrm{GAPDH})$, $\Delta \mathrm{Ct}($ control $)=\Delta \mathrm{Ct}(\mathrm{CYPs})-\Delta \mathrm{Ct}(\mathrm{GAPDH})$.

The primers used for qRT-PCR measurement were: GAPDH forward 5'-GGA GCG

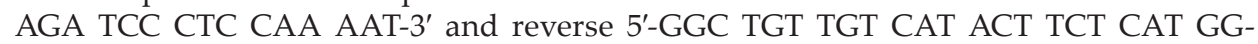
3', NQO1 forward 5'-GAA GAG CAC TGA TCG TAC TGG C-3' and reverse 5'-GGA TAC TGA AAG TTC GCA GGG-3', GSTP1 forward 5'-CCC TAC ACC GTG GTC TAT TTC C-3' and reverse 5'-CAG GAG GCT TTG AGT GAG C-3', GSTM1 forward 5'-TCT GCC CTA CTT GAT TGA TGG G-3' and reverse 5'-TCC ACA CGA ATC TTC TCC TCT-3', CYP1A1 forward 5'-TAC CTC AGC AGC CAC CTC CAA G-3' and reverse 5'-GGC CCT GAT TAC CCA GAA 
TAC C-3', CYP3A4 forward 5'-AAG TCG CCT CGA AGA TAC ACA-3' and reverse 5'-AAG GAG AGA ACA CTG CTC GTG-3', CYP17A1 forward 5'-GCT GCT TAC CCT AGC TTA TTT GT-3' and reverse 5'-ACC GAA TAG ATG GGG CCA TAT TT-3'.

\section{Western blot analysis}

Three days after rutin treatment, proteins in HepG2 cells were extracted with RIPA lysis buffer (Applygen, China). Total protein concentrations of the control and rutin-treated groups were determined with a commercial BCA kit. Ten $\mu \mathrm{g}$ from the samples were loaded into each well and further separated on 7.5\% (for CYP1A1 and CYP3A4) and $10 \%$ (for GSTP1, NQO1 and GAPDH) separating gels in SDS-page electrophoresis. Protein bands were transferred to $0.45-\mu \mathrm{m}$ nitrocellulose membranes (Bio-Rad) and blocked with $5 \%$ non-fat dry milk for $1 \mathrm{~h}$ at room temperature. The membranes were further incubated with specific primary antibodies against CYP1A1, CYP3A4, GSTP1 and NQO1, then with secondary HRP-labeled antibodies, and finally visualized using enhanced chemiluminescence (ECL) solution. Density of protein bands was measured using the Image J software.

\section{Statistical analysis}

Statistical analysis was performed using GraphPad Prism (GraphPad Software v5.0, USA). A two-tailed Student's $t$-test was used to compare the two groups. Results were expressed as mean \pm standard deviation (SD) of three independent experiments and a $p$ value $<0.05$ indicated statistical significance.

\section{RESULTS AND DISCUSSION}

The presence of phenolic $\mathrm{OH}$ and aromatic $\mathrm{H}$ in rutin were proven via ${ }^{1} \mathrm{H}$ NMR spectra (Fig. 1). At $\delta 12.58,10.81,9.65$ and 9.18 ppm, signals showed the existence of phenolic $\mathrm{OH}$ and the signals at $\delta 7.51,6.82,6.36$ and $6.18 \mathrm{ppm}$ showed the presence of aromatic protons. Methyl $\left(\mathrm{CH}_{3}\right)$ and methylene $\left(\mathrm{CH}_{2}\right)$ protons were also observed as doublets at $\delta 5.17$ and $5.08 \mathrm{ppm}$. In the FT-IR spectra, rutin functional groups were also observed. The peaks at 3414 and $3334 \mathrm{~cm}^{-1}$ proved the presence of alcohol $\mathrm{O}-\mathrm{H}$ and phenolic $\mathrm{O}-\mathrm{H}$, respectively. Moreover, the peaks at 1661 and $1593 \mathrm{~cm}^{-1}$ belonged to carbonyl $(C=O)$ and aromatic $C=C$ bands, respectively.

Migration, invasion and colony formation ability of human hepatocellular carcinoma cell line HEPG2 and the possible effects of rutin on that cell were investigated under in vitro conditions.

Cytotoxic effect of rutin on HEPG2 cells was determined using the Alamar blue assay. As shown in Fig. 2a, rutin was demonstrated to have a dose-dependent inhibitory action on the viability of HEPG2 cells and $I C_{50}$ value was calculated as $52.7 \mu \mathrm{mol} \mathrm{L}^{-1}$, by using sigmoidal plot of log rutin concentration $v$ s. cell viability (Fig. 2b). To clarify optimum growth time and cell number, different numbers of HEPG2 cells were incubated in 6-, 12-, 24- and 96 -well plates at $37^{\circ} \mathrm{C}$ in $5 \% \mathrm{CO}_{2}$. Effect of rutin on the growth of HEPG2 cells was also determined and optimum incubation time for further studies was determined. Transfection day was accepted as day 1 and rutin significantly showed its action on cell growth 

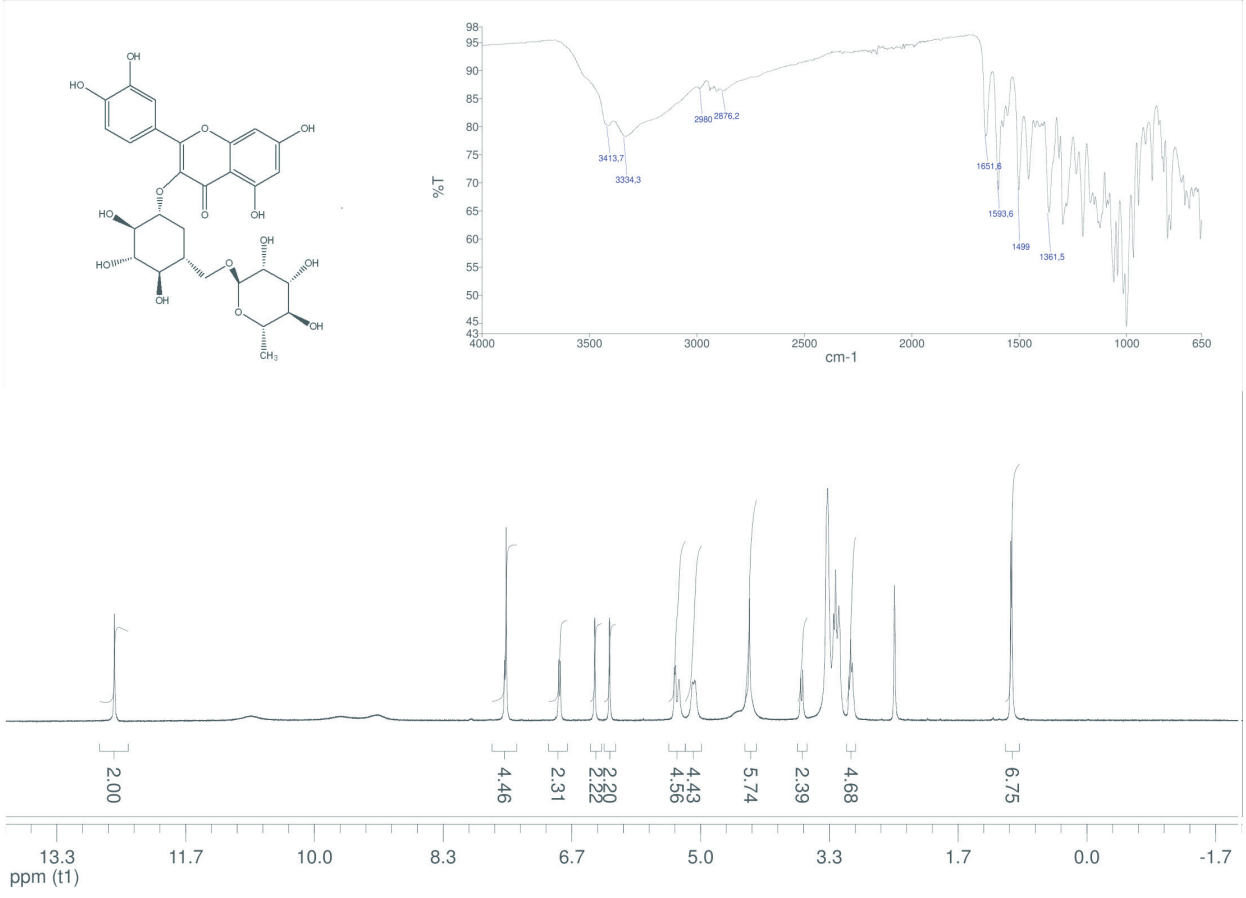

Fig. 1. Spectral characterization of rutin: a) chemical structure of rutin; b) functional groups of rutin by FT-IR; c) ${ }^{1} \mathrm{H}$ NMR spectrum of rutin.

on day 3. Since the untreated cells became confluent between days 4 and 5 , the experiment was stopped at day 5 (Fig. 2c). In order to understand the reason for cell death, the effect of rutin on apoptosis-induced cell death was also investigated using flow cytometry after Annexin V-APC and 7-AAD staining. Treatment by $52.7 \mu \mathrm{mol} \mathrm{L}^{-1}$ of rutin significantly increased (28.9\%) early- and late-stage apoptosis in HEPG2 cells (Fig. 2d).

Wound healing assay was conducted to observe the effects of rutin on the mobility of HEPG2 cells (Fig. 3a). Analysis of wound migration (Fig. 3b) showed that rutin, at 52.7 $\mu \mathrm{mol} \mathrm{L}{ }^{-1}$ significantly inhibited migration of HEPG2 cells. Moreover, anti-invasive potential of rutin was also demonstrated by the Matrigel invasion assay (Fig. 3c) when rutin significantly (21.6\%, $p=0.0018)$ inhibited invasion of HEPG2 cells. Besides, treatment with rutin inhibited $57.4 \%(p<0.0001)$ of colony formation of the invaded cells (Fig. 3d).

In general, treatment of cancerous cell lines with phenolics and flavonoids in particular resulted in inhibition of bioactivating CYP enzyme expressions (18). Decreased level of CYPs prevented formation of toxic metabolites as well as superoxide radicals. CYP3A4 is the dominant P450 enzyme and is responsible for the metabolism of more than $60 \%$ of clinical drugs (19); it starts to express after the postnatal period. A primary form, CYP3A7, is found prominently in human fetal liver microsomes (20). The treatment with rutin inhibited mRNA and protein expression of CYP3A4 enzyme by 73.2 and $75.3 \%$, respectively. 

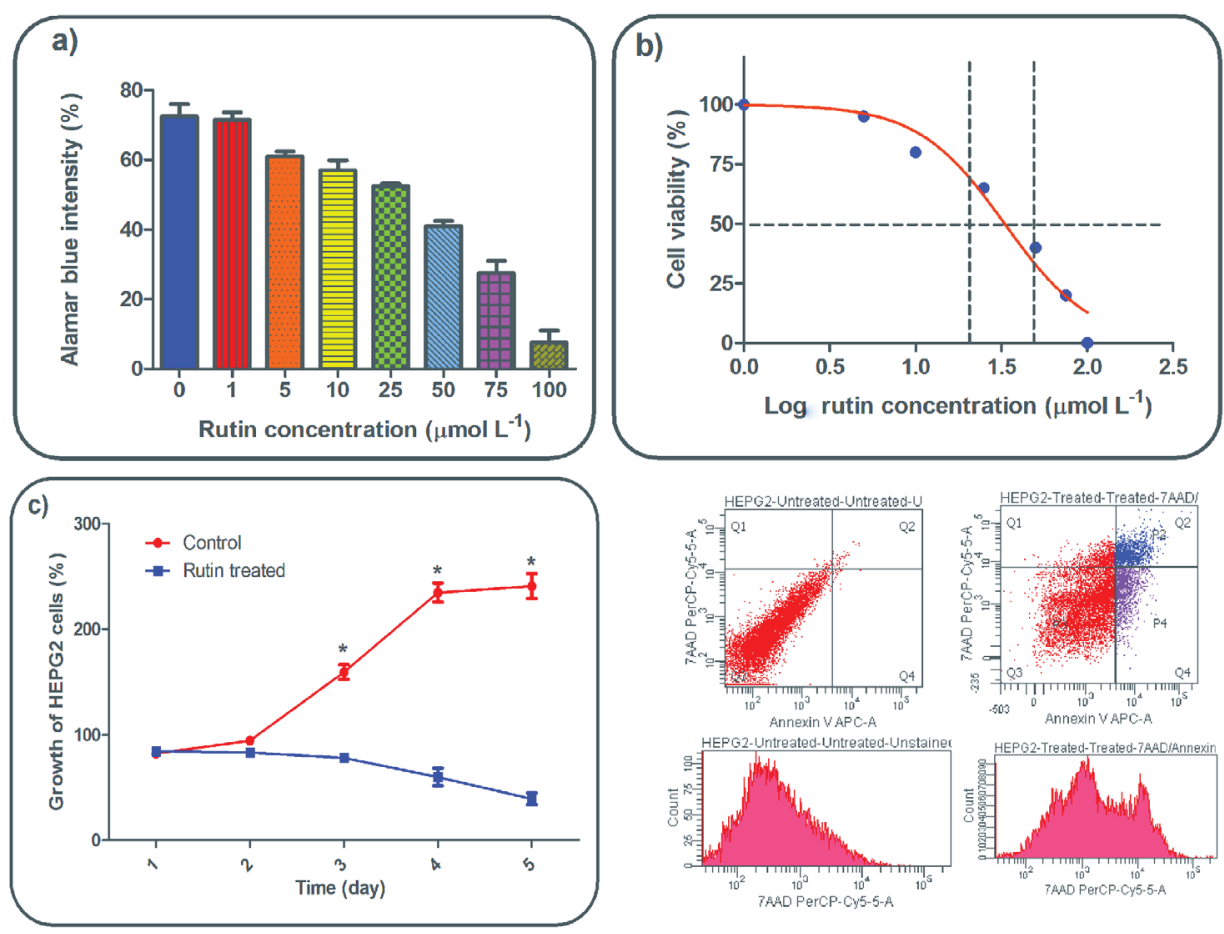

Fig. 2. Effects of rutin on viability and proliferation of HEPG2 cells: a) viability of HEPG2 cells after treatment with different concentrations of rutin measured by Alamar blue assay; $b$ ) $I C_{50}$ value of rutin on HEPG2 cells determined from sigmoidal plot of rutin concentration vs. cell viability; c) Effect of rutin on growth of HEPG2 cells on time scale; d) Effect of rutin on apoptosis-induced cell death examined by flow cytometry following Annexin V-APC and 7-AAD staining. The data of a) and c) are presented as mean $\pm \mathrm{SD}, n=3$. *Statistically significant difference vs. control: $p<0.05$.

Inhibition of this CYP isoform resulted in the alteration of the metabolism of chemotherapeutic drugs used in HCC (16). During combination chemotherapy, the metabolism of the main drug generally requires modification of its regulator by another molecule. Hence, a decreased level of CY3A4 after rutin treatment may increase the efficacy of CYP3A4 inactivating drugs. On the other hand, in many studies, the treatment with flavonoids such as quercetin resulted in induction of CYP1A1 expression (21-23). This is also supported by this study's results (1.7-fold and 2.77-fold induction in protein and mRNA expression, respectively).

Notably, rutin treatment significantly affected protein expression of the drug metabolizing CYP3A4 and CYP1A1, and phase II reaction catalyzing NQO1 and GSTP1 enzymes. Quantitative and comparative analyses were done using Western blotting. Analysis of band density (Fig. 4 b) showed that treatment with rutin significantly reduced CYP3A4 protein expression in HEPG2 $(75.3 \%, p<0.0001)$. On the other hand, interestingly, the other cytochrome P450 dependent enzyme CYP1A1 protein expression (Fig. 4c) was in- 

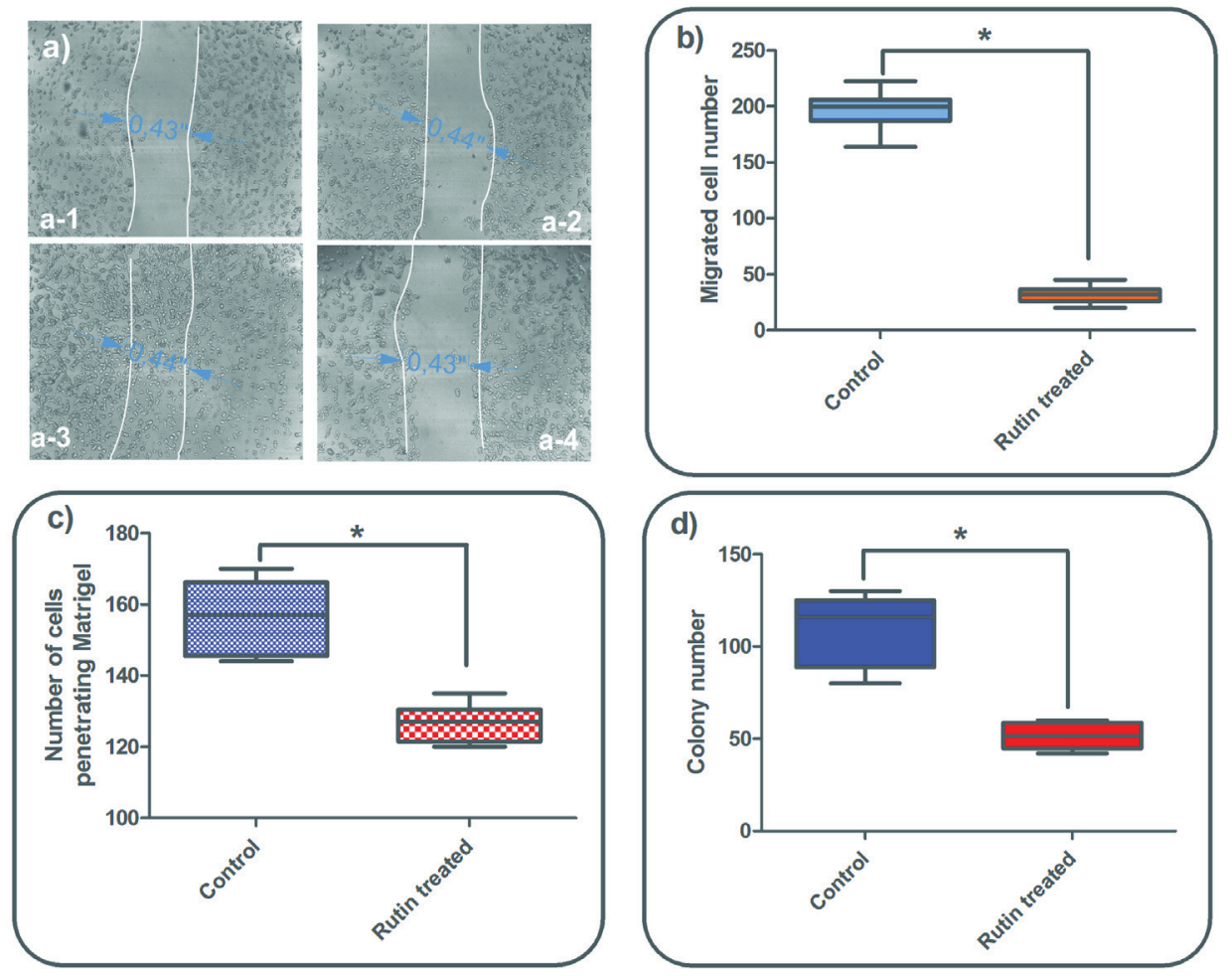

Fig. 3. Effects of rutin on proliferation, migration, invasion and colony formation of HEPG2 cells: a) representative images of wound healing assay: a-1 (0 h)/a-3 (48 h) and a-2 (0 h)/a-4 (48 h) for control and rutin groups, resp; $\mathrm{b}-\mathrm{d}$ ): Quantitative analyses of migration, invasion and colony formation (rates were calculated based on the cell number). Mean \pm SD of three experiments performed in duplicate. *Statistically significant difference $v$ s. control: $p<0.05$.

creased 1.7-fold ( $p=0.0084)$. Besides, antioxidant and phase II reaction catalyzing NQO1 and GSTP1 protein expressions were also elevated 2.42- and 2.03-fold, respectively (Figs. $4 \mathrm{~d}, \mathrm{e})$.

GSP1 is one of the tumor suppressor genes evaluated in many cancer types. Hypermethylation of cysteine which is found in CpG island promoter region causes the loss of GSTP1 activity. Inactivation of GSP1 was found to be associated with the increased risk and shortened survival in patients with $\operatorname{HCC}(24,25)$. This study showed that the mRNA expression elevation was observed in the expression of GSTP1 (9.84-fold), which may be due to demethylation of this promotor region. NQO1, one of the other phase II and antioxidant enzymes, ubiquitously expressed not only in liver but also in other tissues such as lung, colon and breast (26-28). Decreased level of NQO1 activity due to genetic polymorphisms also increases the incidence of $\operatorname{HCC}(29,30)$. On the other hand, the increased level of NQO1 expression was demonstrated to possess protective role in cellular defense 



Fig. 4. Effects of rutin on protein expression of cytochrome P450 dependent CYP3A4 and CYP1A1 and phase II reaction catalyzing NQO1 and GSTP1 of human hepatocellular carcinoma cell line HEPG2. a) Representative immunoblot of HEPG2 cells' protein in experimental control and rutin treated groups. b)-e): Analysis of band density of protein expression of the control and rutin treated groups. The data are presented as mean $\pm \mathrm{SD}, n=3$. Statistically significant difference $v$ s. control: ${ }^{*} p<0.05$, ${ }^{* *} p<0.001$.

during carcinogenesis (31). As seen in Fig. 5, treatment with $52.7 \mu \mathrm{mol} \mathrm{L}{ }^{-1}$ rutin significantly inhibited mRNA expression of CYP3A4 (73.2 \%, $p=0.0014)$ while CYP1A1, NQO1 and GSTP1 mRNA expressions were increased 2.77- $(p=0.029), 4.85-(p=0.0051)$ and 9.84fold $(p<0.0001)$, respectively.

\section{CONCLUSIONS}

In conclusion, the naturally occurring flavonoid rutin significantly inhibited progression of HCC cells. The compound was found remarkably effective on migration, colony formation and invasive potential of HEPG2 cells. Rutin was found to be a very potent inhibitor of CYP3A4 and activator of GSTP1 and NQO1. On the other hand, it should be noted that the in vitro inhibiting and activating potential of rutin on HCC must be supported by in vivo studies. 


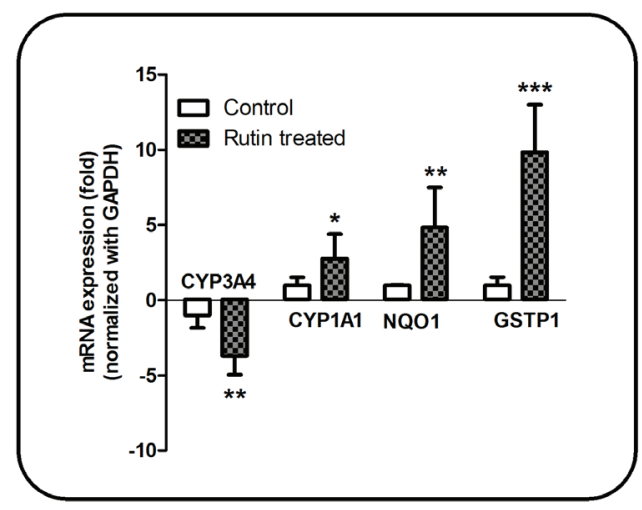

Fig. 5. Effects of rutin on mRNA expressions of cytochrome P450 dependent CYP3A4 and CYP1A1 and phase II reaction catalyzing NQO1 and GSTP1 of human hepatocellular carcinoma cell line, HEPG2. Alterations in mRNA expressions were analyzed by using qRT-PCR. The data are presented as mean $\pm \mathrm{SD}, n=3$. Statistically significant difference $v$ s. control: ${ }^{*} p<0.05,{ }^{* *} p<0.001,{ }^{* * *} p<0.0001$.

Acknowledgments. - This work is supported by The Research Foundation of Selcuk University (project number: 14401126).

Acronyms. - 7-AAD - 7-aminoactinomycin D, BCA - bicinchoninic acid, BSA - bovine serum albumin, CYP - cytochrome P450, ECL - enhanced chemiluminescence, EMEM - Eagle's minimal essential medium, FBS - fetal bovine serum, HCC - hepatocellular carcinoma, PAF - platelet activating factor, RIPA-buffer - radioimmunoprecipitation assay buffer.

\section{REFERENCES}

1. L. A. Torre, F. Bray, R. L. Siegel, J. Ferlay, J. Lortet-Tieulent and A. Jemal, Global cancer statistics, 2012, Cancer J. Clin. 65 (2015) 87-108; DOI: 10.3322/caac.21262.

2. M. Balbi, V. Donadon, M. Ghersetti, S. Grazioli, G. D. Valentina, R. Gardenal, M. D. Mas, P. Casarin, G. Zanette, C. Miranda and P. Cimarosti, Alcohol and HCV chronic infection are risk cofactors of type 2 diabetes mellitus for hepatocellular carcinoma in Italy, Int. J. Environ. Res. Public Health 7 (2010) 1366-1378; DOI: 10.3390/ijerph7041366.

3. X. Zhang and H. G. Ding, Key role of hepatitis B virus mutation in chronic hepatitis B development to hepatocellular carcinoma, World J. Hepatol. 7 (2015) 1282-1286; DOI: 10.4254/wjh.v7.i9.1282.

4. P. C. Hollman and M. B. Katan, Absorption, metabolism and health effects of dietary flavonoids in man, Biomed. Pharmacother. 51 (1997) 305-310; DOI: 10.1016/S0753-3322(97)88045-6.

5. E. Middleton, C. Kandaswami and T. C. Theoharides, The effects of plant flavonoids on mammalian cells: implications for inflammation, heart disease, and cancer, Pharmacol. Rev. 52 (2000) 673-751.

6. G. Williamson and C. Manach, Bioavailability and bioefficacy of polyphenols in humans. II. Review of 93 intervention studies, Am. J. Clin. Nutr. 81 (2005) 243S-255S.

7. B. A. Graf, C. Ameho, G. G. Dolnikowski, P. E. Milbury, C. Y. Chen and J. B. Blumberg, Rat gastrointestinal tissues metabolize quercetin, J. Nutr. 136 (2006) 39-44. 
8. S. Scholz and G. Williamson, Interactions affecting the bioavailability of dietary polyphenols in vivo, Int. J. Vitam. Nutr.Res. 77 (2007) 224-235; DOI: 10.1024/0300-9831.77.3.224.

9. V. A. Kostyuk, A. I. Potapovich, T. V. Kostyuk and M. G. Cherian, Metal complexes of dietary flavonoids: evaluation of radical scavenger properties and protective activity against oxidative stress in vivo, Cell. Mol. Biol. (Noisy-le-grand) 53 (2007) 62-69; DOI: 10.1170/T776.

10. K. Song, J. Y. Na, S. Kim and J. Kwon, Rutin upregulates neurotrophic factors resulting in attenuation of ethanol-induced oxidative stress in HT22 hippocampal neuronal cells, J. Sci. Food Agric. 95 (2015) 2117-2123; DOI: 10.1002/jsfa.6927.

11. B. L. Santos, A. R. Silva, B. P. Pitanga, C. S. Sousa, M. S. Grangeiro, B. O. Fragomeni, P. L. Coelho, M. N. Oliveira, N. J. Menezes-Filho, M. F. Costa, R. S. El-Bachá, E. S. Velozo, G. P. Sampaio, S. M. Freire, M. Tardy and S. L. Costa, Antiproliferative, proapoptotic and morphogenic effects of the flavonoid rutin on human glioblastoma cells, Food Chem. 127 (2011) 404-411; DOI: 10.1016/j.foodchem.2010.12.13.

12. N. Ihme, H. Kiesewetter, F. Jung, K. H. Hoffmann, A. Birk, A. Müller and K. I. Grützner, Leg oedema protection from a buckwheat herb tea in patients with chronic venous insufficiency: a single-centre, randomised, double-blind, placebo-controlled clinical trial, Eur. J. Clin. Pharmacol. 50 (1996) 443-447; DOI: 10.1007/s002280050138.

13. S. Okonogi, R. Khonkarn, S. Mankhetkorn, F. M. Unger and H. Viernstein, Antioxidant activity and cytotoxicity of Cyrtosperma johnstonii extracts on drug sensitive and resistant leukemia and small cell lung carcinoma cells, Pharm. Biol. 51 (2013) 329-338; DOI: 10.3109/13880209.2012.729064.

14. H. J. You, H. J. Ahn and G. E. Ji, Transformation of rutin to antiproliferative quercetin-3-glucoside by Aspergillus niger, J. Agric. Food Chem. 58 (2010) 10886-10892; DOI: 10.1021/jf102871g.

15. F. P. Guengerich, Cytochrome P-450 3A4: regulation and role in drug metabolism, Annu. Rev. Pharmacol. Toxicol. 39 (1999) 1-17; DOI: 10.1146/annurev.pharmtox.39.1.1.

16. U. M. Zanger and M. Schwab, Cytochrome P450 enzymes in drug metabolism: regulation of gene expression, enzyme activities, and impact of genetic variation, Pharmacol. Ther. 138 (2013) 103-141; DOI: 10.1016/j.pharmthera.2012.12.007.

17. K. Ohkura, Y. Kawaguchi, Y. Watanabe, Y. Masubuchi, Y. Shinohara and H. Hori, Flexible structure of cytochrome P450: promiscuity of ligand binding in the CYP3A4 heme pocket, Anticancer Res. 29 (2009) 935-942.

18. E. Arinç, D. Yilmaz and A. Bozcaarmutlu, Mechanism of inhibition of CYP1A1 and glutathione S-transferase activities in fish liver by quercetin, resveratrol, naringenin, hesperidin, and rutin, Nutr. Cancer 67 (2015) 137-144; DOI: 10.1080/01635581.2015.965335.

19. T. Fujimura, S. Takahashi, T. Urano, T. Tanaka, W. Zhang, K. Azuma, K. Takayama, D. Obinata, T. Murata, K. Horie-Inoue, T. Kodama, Y. Ouchi, Y. Homma and S. Inoue, Clinical significance of steroid and xenobiotic receptor and its targeted gene CYP3A4 in human prostate cancer, Cancer Sci. 103 (2012) 176-180; DOI: 10.1111/j.1349-7006.2011.02143.x.

20. J. C. Stevens, R. N. Hines, C. Gu, S. B. Koukouritaki, J. R. Manro, P. J. Tandler and M. J. Zaya, Developmental expression of the major human hepatic CYP3A enzymes, J. Pharmacol. Exp. Ther. 307 (2003) 573-582; DOI: 10.1124/jpet.103.054841.

21. H. P. Ciolino, P. J. Daschner and G. C. Yeh, Dietary flavonols quercetin and kaempferol are ligands of the aryl hydrocarbon receptor that affect CYP1A1 transcription differentially, Biochem. J. 340 (1999) 715-722; DOI: 10.1042/bj3400715.

22. R. Vrba, R. Aujeský and C. Neoral, Results of limited resection of carcinoma of the gastroesophageal junction, Rozhl. Chir. 91 (2012) 368-372.

23. Mohammadi-Bardbori, J. Bengtsson, U. Rannug, A. Rannug and E. Wincent, Quercetin, resveratrol, and curcumin are indirect activators of the aryl hydrocarbon receptor (AHR), Chem. Res. Toxicol. 25 (2012) 1878-1884; DOI: 10.1021/tx300169e. 
24. L. Rongrui, H. Na, L. Zongfang, J. Fanpu and J. Shiwen, Epigenetic mechanism involved in the HBV/HCV-related hepatocellular carcinoma tumorigenesis, Curr. Pharm. Des. 20 (2014) 1715-1725; DOI: 10.2174/13816128113199990533.

25. M. Kiran, Y. K. Chawla and J. Kaur, Methylation profiling of tumor suppressor genes and oncogenes in hepatitis virus-related hepatocellular carcinoma in northern India, Cancer Genet. Cytogenet. 195 (2009) 112-119; DOI: 10.1016/j.cancergencyto.2009.06.021.

26. D. Ross, J. K. Kepa, S. L. Winski, H. D. Beall, A. Anwar and D. Siegel, NAD(P)H:quinone oxidoreductase 1 (NQO1): chemoprotection, bioactivation, gene regulation and genetic polymorphisms, Chem. Biol. Interact. 129 (2000) 77-97; DOI: 10.1016/S0009-2797(00)00199-X.

27. P. Joseph, T. Xie, Y. Xu and A. K. Jaiswal, NAD(P)H:quinone oxidoreductase1 (DT-diaphorase): expression, regulation, and role in cancer, Oncol. Res. 6 (1994) 525-532.

28. E. A. Rosvold, K. A. McGlynn, E. D. Lustbader and K. H. Buetow, Identification of an NAD(P) H:quinone oxidoreductase polymorphism and its association with lung cancer and smoking, Pharmacogenetics 5 (1995) 199-206.

29. Y. Fan, D. Hu, B. Feng and W. Wang, The NQO1 C609T polymorphism and hepatocellular carcinoma risk, Tumour Biol. 35 (2014) 7343-7350; DOI: 10.1007/s13277-014-1712-8.

30. H. Akkiz, S. Bayram, A. Bekar, E. Akgöllü, Y. Ülger, B. Y. Kaya, M. Sandikçi and B. Özdil, No association of $\mathrm{NAD}(\mathrm{P}) \mathrm{H}$ : quinone oxidoreductase 1 (NQO1) C609T polymorphism and risk of hepatocellular carcinoma development in Turkish subjects, Asian Pac. J. Cancer Prev. 11 (2010) 10511058.

31. M. Belinsky and A. K. Jaiswal, NAD(P)H:quinone oxidoreductase1 (DT-diaphorase) expression in normal and tumor tissues, Cancer Metastasis Rev. 12 (1993) 103-117; DOI: 10.1007/BF00689804. 